\title{
Correcting India's Chronic Shortage of Drug Inspectors to Ensure the Production and Distribution of Safe, High- Quality Medicines
}

\section{Abhay B. Kadam ${ }^{1 *}$, Karen Maigetter ${ }^{2,3}$, Roger Jeffery ${ }^{4}$, Nerges F. Mistry ${ }^{1}$, Mitchell G. Weiss ${ }^{2,3}$, Allyson M. Pollock}

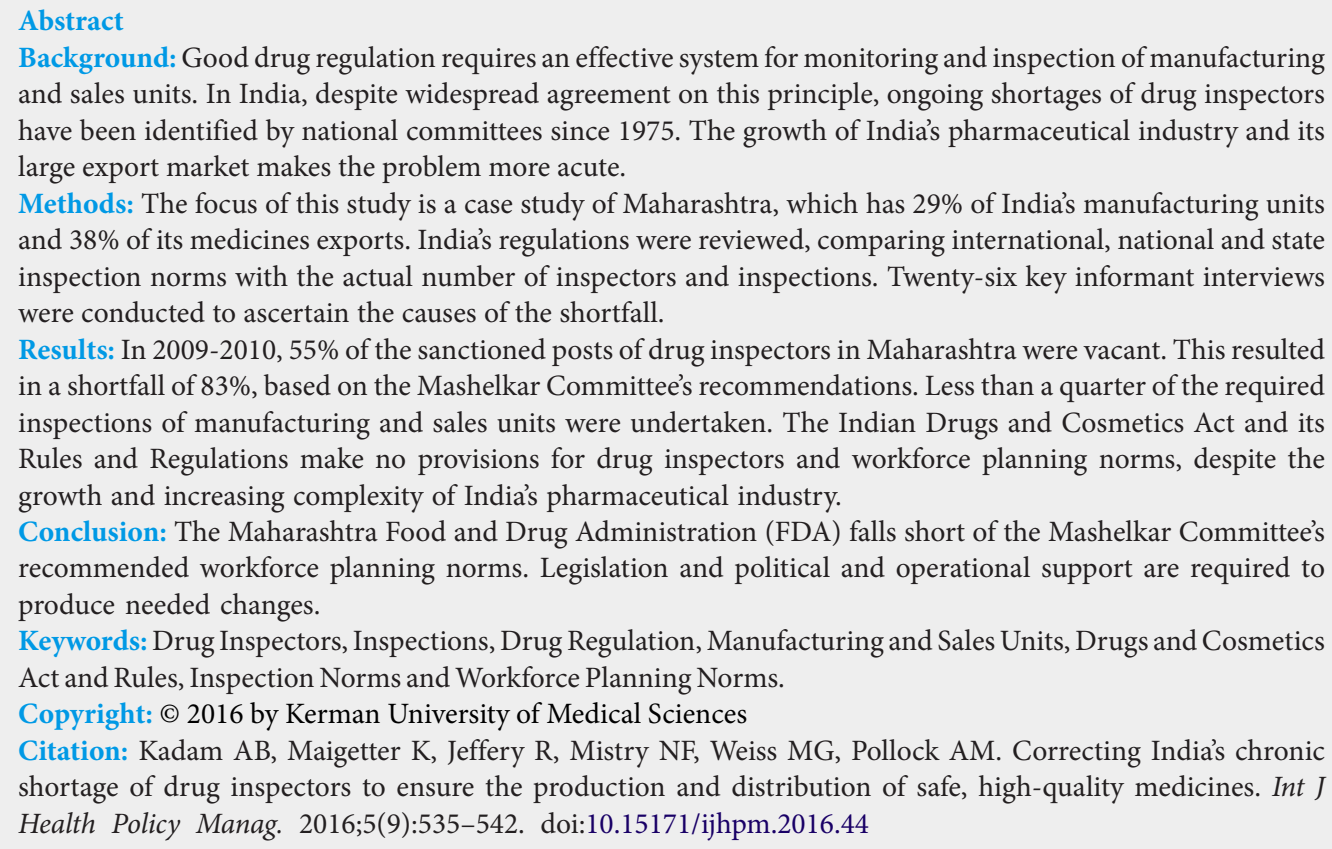

Background: Good drug regulation requires an effective system for monitoring and inspection of manufacturing and sales units. In India, despite widespread agreement on this principle, ongoing shortages of drug inspectors have been identified by national committees since 1975. The growth of India's pharmaceutical industry and its large export market makes the problem more acute.

Methods: The focus of this study is a case study of Maharashtra, which has $29 \%$ of India's manufacturing units and $38 \%$ of its medicines exports. India's regulations were reviewed, comparing international, national and state inspection norms with the actual number of inspectors and inspections. Twenty-six key informant interviews were conducted to ascertain the causes of the shortfall.

Results: In 2009-2010, 55\% of the sanctioned posts of drug inspectors in Maharashtra were vacant. This resulted in a shortfall of $83 \%$, based on the Mashelkar Committee's recommendations. Less than a quarter of the required inspections of manufacturing and sales units were undertaken. The Indian Drugs and Cosmetics Act and its Rules and Regulations make no provisions for drug inspectors and workforce planning norms, despite the growth and increasing complexity of India's pharmaceutical industry.

Conclusion: The Maharashtra Food and Drug Administration (FDA) falls short of the Mashelkar Committee's recommended workforce planning norms. Legislation and political and operational support are required to produce needed changes.

Keywords: Drug Inspectors, Inspections, Drug Regulation, Manufacturing and Sales Units, Drugs and Cosmetics Act and Rules, Inspection Norms and Workforce Planning Norms.

Copyright: @ 2016 by Kerman University of Medical Sciences

Citation: Kadam AB, Maigetter K, Jeffery R, Mistry NF, Weiss MG, Pollock AM. Correcting India's chronic shortage of drug inspectors to ensure the production and distribution of safe, high-quality medicines. Int $J$ Health Policy Manag. 2016;5(9):535-542. doi:10.15171/ijhpm.2016.44

\section{Article History:}

Received: 20 September 2015

Accepted: 16 April 2016

ePublished: 27 April 2016
*Correspondence to:

Abhay B. Kadam

Email: abhay_kadam7@yahoo.co.in

\section{Key Messages}

\section{Implications for policy makers}

- To assess needs and to overcome the shortage of drug inspectors, workforce planning norms need to be clarified, and governmental commitment to their implementation should be strengthened.

- Given the growth and complexity of the pharmaceutical industry, legal provisions may be required to ensure that adequate drug inspections take place.

Implications for the public

All drug regulatory systems must have a strong inspectorate to ensure the production and distribution of safe and high-quality medicines. This study shows how the Indian Drugs and Cosmetics Act and its Rules make no provisions for drug inspectors and workforce planning norms, despite the growth and increasing complexity of India's pharmaceutical industry. For example, the Maharashtra Food and Drug Administration (FDA) falls short of the Mashelkar Committee's recommended workforce planning norms: oversight of the manufacturing and marketing of pharmaceuticals is weak at all levels. Legislation and political and operational support are required to produce much needed change. We recommend that the Central Drug Standard Control Organization (CDSCO) implement workforce standards and publish annually data on numbers of drug inspectors, inspections conducted, action against non-compliance, samples collected and tested, and substandard and spurious medicines identified at federal and state level. These data should be placed in the public domain to enable public scrutiny and parliamentary accountability.

\section{Background}

Growth of Indian Pharmaceutical Industry and Challenges for Drug Regulation

In 1947, at India's independence, pharmaceutical sales in India were dominated by the imports of foreign multinational companies, which controlled about $90 \%$ of the market. In 1970 , the Government of India implemented a series of initiatives to stimulate the growth of an autonomous Indian pharmaceutical industry. It established three new state-owned pharmaceutical companies, bringing the total number to five. It also replaced the colonial intellectual property laws codified in the 1911 Indian Patents and Designs Act with a new Patent Act, which allowed Indian companies to make generic copies of existing drugs if they followed a different manufacturing 
process. Using 'reverse engineering' Indian companies began to produce bulk drugs at much cheaper prices than the originals. This shift from product patents to process patents, in combination with new rules that placed restrictions on the proportion of shares multinational companies could hold in Indian companies, enabled the Indian pharmaceutical industry to flourish. ${ }^{1}$

By 1990, India had become self-sufficient in the production of formulations and was close to self-sufficiency in the manufacture of bulk drugs. India joined the World Trade Organization (WTO) in 1995, and in 2005 it introduced new laws to comply with the WTO Agreement on Trade-Related Aspects of Intellectual Property Rights (TRIPS), which reestablished the product patent regime. Today, India is a major producer and exporter of generic medicines with an estimated 10500 pharmaceutical manufacturing units and approximately 600000 sales units. ${ }^{2}$ Indian pharmaceutical companies produce around 60000 generic drugs and over 400 bulk drugs used in formulations. ${ }^{1}$ Nevertheless, its reputation has been tarnished by claims that it produces and distributes low-quality, irrational, substandard, and spurious medicines. ${ }^{3-8}$ In the last decade $7 \%-8 \%$ of drug samples tested in the country were found to be substandard. ${ }^{2}$ Maharashtra has $29 \%$ of the country's manufacturing units and accounts for $38 \%$ of India's exports of medicines. ${ }^{9}$ According to the annual plan report for 2011-2012 of the Medical Education and Drugs Department, $8 \%$ of the drug samples tested were deemed substandard during 2009-2010. ${ }^{10}$

In January 2012, the US Food and Drug Administration (FDA) issued a permanent injunction against two manufacturing units of the pharmaceutical giant Ranbaxy Laboratories Ltd. for their lack of compliance to Current Good Manufacturing Practice (CGMP).${ }^{11}$ In 2013, the Government of India asked the Drug Controller General of India (DCGI) to review CGMP compliance of all units of Ranbaxy. ${ }^{12}$ In January 2014, the US FDA added one more unit of Ranbaxy to its injunction ${ }^{11}$ despite the DCGI's favourable national review of all units of Ranbaxy in 2013.

All this highlights the importance of drug inspection, quality monitoring and the role of drug inspectors in maintaining standards and ensuring trust in India's pharmaceuticals production. In order to assess the capacity and quality of India's inspection procedures, information concerning the approved drugs in the country, the number of drug inspectors, the number of inspections conducted and the actions in response to non-compliance need to be analysed. Unfortunately, these data are rarely available in the public domain, and indirect methods for analysis must be used.

Regulatory Structure in India and the Responsibilities of Drug Inspectors

Under the Drugs and Cosmetics Act, the regulation of the manufacture, sale and distribution of drugs is primarily the concern of the State authorities (State FDAs). The Central Drug Standard Control Organization (CDSCO) is responsible for approval of new drugs, clinical trials in the country, laying down the standards for drugs, control over the quality of imported drugs, coordination of the activities of State FDAs, and providing expert advice to bring about uniformity in the enforcement of the relevant Act. ${ }^{13}$
In each state, drug inspectors are responsible for the inspection of all manufacturing, distribution and sales units, to ensure that manufacturing, sales, distribution, storage and dispensing of medicines proceeds according to the relevant rules and regulations, as amended from time to time, under the Drugs and Cosmetics Act of 1940, and the Drugs and Cosmetics Rules of 1945. Additionally, they are responsible for taking drug samples for testing, conducting raids, taking action against non-compliance, following up legal actions, recalling non-compliant drugs, enforcing drug price control orders, and regulating drug advertising and drug promotion (pp. 53-54). ${ }^{13}$

History of the Gap in National Statutory Provisions for Inspector and Workforce Norms

For more than four decades national committees have highlighted the shortage of drug inspectors in India. Part of the problem lies in the division of powers and responsibilities between States and the National (Central) government, described in the previous section.

In India, 'the regulation of manufacture, sale and distribution of drugs is primarily the concern of the State authorities. ${ }^{\text {'13 }}$ Section 21 of the Drugs and Cosmetics Act 1940 indicates that the Central Government and the State Government have the 'power' but not the 'duty' to appoint drug inspectors. Sections 22 and 23, respectively, provide the powers and procedures of inspectors. Section 33 indicates that the Central Government may make rules to stipulate the qualifications of inspectors. The Drugs and Cosmetics Rules 1945 indicate inspector's qualifications (in Rule 49) and duties (in Rules 51 and 52). 'Inspection norms,' however, are not indicated separately in the Act or in the Rules; they are only mentioned under duties of inspectors (Rules 51 and 52). Additionally, both the Act and the Rules lack 'workforce planning norms' for estimating the required number of drug inspectors. ${ }^{13}$

The 1975 Hathi Committee drew attention to the shortage of inspectors, a position which had changed little by 2003 . The Mashelkar Committee in 2003 reported that the growth in the number of inspectors had not kept pace with the growth of the industry. At that time, there were only 935 inspectors nationwide. The Mashelkar Committee estimated that 1720 drug inspectors were needed. By 2012, the 59th Parliamentary Standing Committee estimated a need for 3200 drug inspectors-many more than the 1349 sanctioned postsand seriously problematic in as much as only 846 of these sanctioned positions were actually filled (Box 1).,14,15

Box 1 summarises the key reports and findings of government committees over the last four decades in respect of inadequate testing facilities and shortages of drug inspectors. ${ }^{2,14-17}$ The Government has implemented the recommendations of these and other committees only to a limited extent. The Working Group on Drugs and Food Regulation for the 12th Five Year Plan (2012-2017) have proposed achieving compliance with the Mashelkar Committee recommendations by the end of the Plan period. ${ }^{17}$

Lack of Both Data to Assess and Infrastructure to Perform Drug Inspections

National committee reviews have highlighted key concerns about inadequate data and infrastructure to assess needs 
Box 1. Shortage of Inspectors Reported Over Four Decades

Hathi Committee report on drugs and the pharmaceutical industry, 1975 (Chapter IX, para 8) 14 $^{14}$

"... the level of enforcement in most of the States is far from satisfactory. The main reasons for this unsatisfactory state are the varying standards of inspection and licensing of drugs firms and the lack of qualified officers in most of the States to supervise drug control operations."

(This committee estimated 480 drug inspectors were required in the states against the available 369 ).

Task force appointed by Government of India, 1982 (Quoted by Mashelkar Committee Report) ${ }^{15}$

"... the number of drug inspectors in the States should be increased in keeping with the number of manufacturing and selling premises licensed."

Lentin Commission, 1986 (page iii, para 1$)^{16}$

The foreword of this report says, 'These pages describe and illustrate the ugly facets of the human mind and human nature, projecting errors of judgement misuse of ministerial power and authority, apathy towards human life, corruption, nexus and quid pro quo between unscrupulous license holders, analytical laboratories elements in the industries department controlling the award of rate contracts, manufacturers, traders, merchants, suppliers, the Food and Drugs Administration and persons holding ministerial rank.'

Dr. Mashelkar Committee, 2003 (page 2, para 3) ${ }^{15}$

"... the problems in the regulatory system in the country were primarily due to inadequate or weak drug control infrastructure at the State and Central level, inadequate testing facilities, shortage of drug inspectors, non-uniformity of enforcement, lack of specially trained cadres for specific regulatory areas, non-existence of data bank and non-availability of accurate information."

(This committee estimated a requirement of 1720 drug inspectors in the states against the available 935).

Working Group on Drugs and Food Regulation for the 12th Five Year Plan (2012-2017) (page 8, para 1) ${ }^{17}$

"Strengthening of Drugs Regulatory Mechanisms is one of the major public health interventions. This ensures that safe, efficacious and quality drugs are made available to the people. Keeping in view the recommendations of the Mashelkar Committee, it is important that the infrastructure, both physical and human resource, both at the Centre as well as in the States is substantially augmented."

59th Parliamentary Standing Committee report, May 2012 (Page 18, para 2)

"... there were approximately 600000 retail sales outlets and around 10500 manufacturing units in the country, which, require just over 3200 Drugs Inspectors. However, in reality, there were only 846 Drugs Inspectors in place against 1349 sanctioned posts in States. Hence, the main problem faced by the States Drug Authorities was inadequate infrastructure, shortage of drugs inspectors, non-existence of data bank and accurate information...."

and performance and to fulfil obligations for drug inspections. The Mashelkar Committee Report (2003) and the 59th Parliamentary Standing Committee Report (May 2012) acknowledged the non-existence of data banks and lack of accurate information as problems for the drug regulatory system. ${ }^{2,15}$ The Indian market has a huge number of products, and many trade names (brand names) for approved formulations. CDSCO has a database of approved formulations but lacks a database for manufacturing licences issued under various trade names by the State FDAs. Information on the number of sanctioned posts of drug inspectors and the actual number of drug inspectors in the different states are not publicly available on the CDSCO website, and few of the state FDAs have their own websites. Essential monitoring information - such as the numbers of inspections conducted, actions against non-compliance, numbers of samples collected and tested, numbers of substandard and spurious medicines detected from tested samples - are not made available by CDSCO.

Weak infrastructure and inadequate capacity are also problems. Over four decades these committees have repeatedly drawn attention to inadequate or weak drug control infrastructure, including lack of manpower at CDSCO, inadequate testing facilities, shortage of drug inspectors, nonuniformity of enforcement and lack of specially trained cadres to assess specific regulatory requirements. ${ }^{2,14,15,17}$

With regard to inspectors and inspection systems, the Mashelkar Committee identified the following problems: - lack of effective coordination between Centre and states
- slow recruitment process

- administrative complexities and lack of a performance management system

- insufficient administrative, professional, and financial support

- non-uniformity in the interpretation of laws and their implementation

- incompetence of regulatory officials

It also recommended time and motion studies to determine how much time is needed by drug inspectors for inspections, as well as for administrative processes, for the assessment of samples collected, for raids, for hearings for legal cases of non-compliance, and for training.

The findings of the 59th Parliamentary Standing Committee were similar. They highlighted the impact of inadequate resources and support from the Central Government. ${ }^{2}$ In response, the 12th 5-year plan recommended a centrally sponsored scheme with $60 \%$ finance provided from the Centre and $40 \%$ from the States. ${ }^{17}$

This paper clarifies the context of these concerns, providing a brief account of the normative regulatory requirements for inspection, key concerns of national committees with respect to drug inspection, and a case study of an important State to analyse shortfalls in the number of inspectors, their causes, implications and possible solutions.

\section{Methods}

The study was undertaken as part of a larger project, Accessing Medicines in Africa and South Asia (AMASA), funded by the 
European Union Seventh Framework Programme (EU-FP7) (http://www.amasa-project.eu/). One of the research topics in the AMASA project was the study of regulatory systems and policies for production, quality control and distribution and prescribing and dispensing of medicines. In our case study, we examine existing national and international policies and regulations with respect to drug inspection in the large Indian state, Maharashtra, with its substantial production capacity.

\section{Study Setting}

The study was conducted in the state of Maharashtra, which is the location of $29 \%$ of India's manufacturing units accounting for $38 \%$ of the country's exports of medicines. It is foremost among the seven states that generate $75 \%$ of India's drug manufacturing capacity. They were designated as category 1 states in the Mashelkar Committee report ${ }^{[1]}$. Maharashtra also has the largest number of sales units of all Indian States. In the context of the AMASA project, we selected four districts: Dhule, Sangli, Nagpur, and Mumbai city, thereby considering the diverse areas of North, South, East, and West zones of Maharashtra, respectively (Figure).

\section{Study Design and Data Collection}

Information about regulatory capacities was collected from annual reports and government documents on the websites of central and state-level drug regulatory agencies (CDSCO, Maharashtra FDA, etc) and of ministries and related departments. Web-based searches of the main Maharashtra newspapers and a search of the archives of Pharmabiz, an online pharmaceuticals information service, focussed on information related to the shortage of drug inspectors, its causes and implications. Information about the number of manufacturing and sales units, and the number of inspections conducted, was obtained from a hard copy of the annual plan of the Medical Education and Drugs Department, Maharashtra Government for the year 2011-2012, which was shared with us by one of the key informants we interviewed. Between November 2011 and June 2012 we conducted 26 key informant interviews with 13 regulatory officials, 4 district-level representatives of the Druggists and Chemists Association, 3 Ministry of Health and public health officials, 3 pharmaceutical producers, and 3 civil society activists. The key informants were purposively selected based on their positions and responsibilities, and by the priority given to drug regulation indicated by the mandate of the organisations. The availability and willingness of respondents to be interviewed was another consideration. Researchers who conducted and analysed these interviews included AMASA project partner organizations in India, the United kingdom, and Switzerland. All had substantial experience with conducting qualitative interview methods and had backgrounds in social science, public health or pharmaceutical development. The key informant interviews were conducted in the local language and English using interview guides with open-ended questions covering topical interests in regulatory structure and capacity, infrastructure, workload management, and enforcement of regulations. The interviews were audio recorded.

Approach to Data Analysis

Global and national norms for the frequency of drug

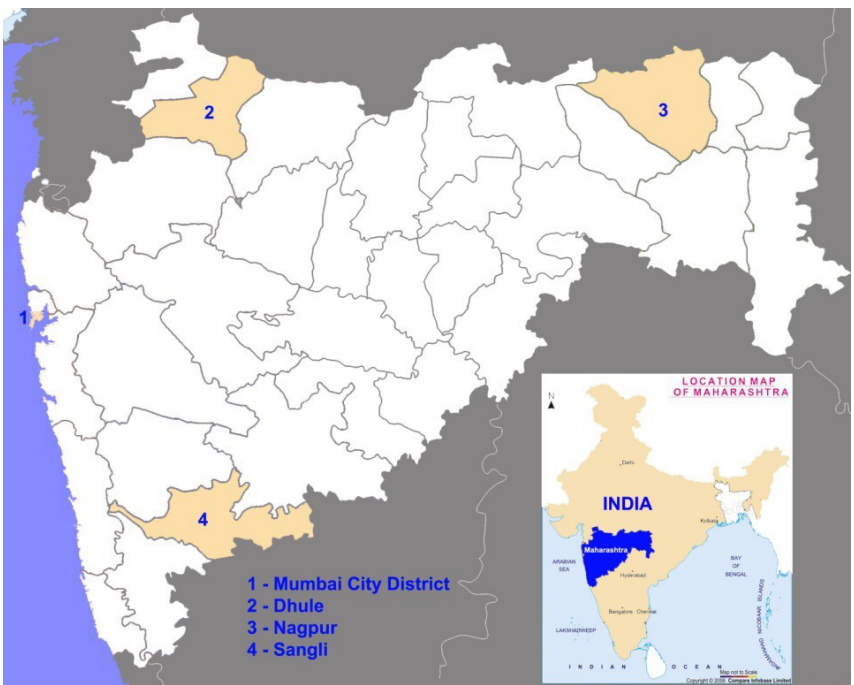

Figure. Selected Study Districts From Maharashtra, India.

inspections and the strength of the drug inspector workforce were tabulated for comparison with Indian norms, based on the Drugs and Cosmetics Act and Rules.

Documentary sources were analysed and tabulated to compare the number of manufacturing and sales units, and, where data were available, indicators of the regulatory capacity for India, Maharashtra, and the district study sites.

The qualitative data from the key informant interviews were transcribed, translated and then processed using the qualitative data analysis software, MAXQDA version 10. Thematic codes were generated deductively, based on topics of the interview guide, to identify issues concerning the shortfall of inspectors according to our respondents.

\section{Results}

Comparisons of Inspection and Workforce Norms

Recommendations for the frequencies of drug inspections and the strength of the drug inspector workforce were compiled, and they are presented in Table 1 . These recommendations are from reports of the World Health Organization (WHO), the US FDA and the Medicines and Healthcare Products Regulatory Agency (MHRA). Workforce planning norms of the Mashelkar Committee ${ }^{15}$ and the Maharashtra FDA ${ }^{10}$ have also been compiled.

Compared with recommendations of the global agencies, Indian norms require more frequent inspections - 'not less than once a year.' Until amended in September 2001, the requirement had been even more demanding - 'not less than twice a year.' The other global and national recommendations have not indicated workforce planning norms. WHO's multi-country study on effective drug regulation (2002) acknowledged the wide international range in the number of units covered by drug inspectors, from a low of 45 to a high of $500 .^{18}$

According to the Maharashtra State FDA officials and the State FDA Annual Action Plan Report, a drug inspector must inspect 10 manufacturing units per month or 21 distribution/ sales units per month. Although this is not a clear workforce planning norm, it can be used to estimate the number of drug inspectors required to inspect all manufacturing, distribution and sales units in the state at least once a year (Table 1). It is 
Table 1. Recommended Frequency of Inspection and Strength of the Drug Inspector Workforce for Manufacturing and Distribution Units According to Authoritative Sources

\begin{tabular}{|c|c|c|}
\hline Authority & Manufacturing Units & Distribution Units \\
\hline \multicolumn{3}{|l|}{ Frequency of inspection } \\
\hline India: Drugs and Cosmetics Act and Rules ${ }^{13}$ (pp. 53-54) & Not less than once a year & Not less than once a year \\
\hline WHO & Once every 2 years & At least once every $12-18$ months \\
\hline US FDA & Every 2 years & Every 2 years \\
\hline UK (MHRA) & Every 2 years & Every 3 years \\
\hline \multicolumn{3}{|l|}{ Drug inspector workforce strength } \\
\hline Mashelkar Committee ${ }^{15}$ (pp. 48-49) & One drug inspector for 50 units & One drug inspector for 200 units \\
\hline $\begin{array}{l}\text { Maharashtra State Food and Drug Regulatory Authority } \\
(\text { State FDA })^{10} \text { (p. A21) }\end{array}$ & 10 inspections per drug inspector per month & 21 inspections per drug inspector per month \\
\hline
\end{tabular}

Abbreviations: WHO, World Health Organization; MHRA, Medicines and Healthcare Products Regulatory Agency; FDA, Food and Drug Administration.

not possible to say how these norms relate to those of other States, because these data are not available in any report nor on the websites of other State FDAs (where such websites exist).

There is no information available to explain how the workforce planning norms of the Maharashtra State FDA were derived. The Mashelkar Committee recommendation of 2003 can be traced back to 1982. In June that year, a Task Force appointed by the Government of India recommended 'one drug inspector for 25 manufacturing units or 100 sales units.' In August 2001, the validity of manufacture and sales licences was extended by the Government from 2 years to 5 years $^{[2]}$. This extension further amended the requirement of statutory inspections of manufacturing and sales units from 'not less than twice a year' to 'not less than once a year. $\left.{ }^{\text {' }}\right]$ Based on this, the Mashelkar Committee revised the earlier recommendation to 'one drug inspector for 50 manufacturing units or 200 sales units.'15

Regulatory Capacities in Maharashtra Compared to Planning Norms

Table 2 shows the number of manufacturing and sales units, the number of expected and actual inspections; and the expected, actual and sanctioned number of drug inspectors with reference to two norms. In 2009-2010, Maharashtra had a $78 \%$ and an $83 \%$ shortfall of drug inspectors in filled posts based on the Maharashtra FDA and Mashelkar Committee norms, respectively. Additionally, the number of posts that were actually filled (73) was $45 \%$ of sanctioned posts (161). In 2009-2010, the shortfall of drug inspectors in post was $100 \%$ in Dhule, $76 \%$ in Nagpur and $89 \%$ in Sangli against the workforce planning norms of the Maharashtra FDA, and $100 \%$ in Dhule, $82 \%$ in Nagpur and $92 \%$ in Sangli against the workforce planning norms recommended by the Mashelkar Committee. In 2009-2010, only 23\% of the required inspections were actually conducted in Maharashtra; in the study districts it was $24 \%$ in Nagpur and $11 \%$ in Dhule and Sangli.

Acknowledging and Explaining the Shortage of Drug Inspectors

The Druggists and Chemists Association members we interviewed and other key informants acknowledged the existence of these shortfalls, confirming our analysis of insufficient human resources at the district level:

"For the last three years there was an insufficient number of drug inspectors in the district. For the first time FDA has enough staff, so now hopefully the work will be done properly. But compared to the workload, it is still not sufficient" (Member of Druggists and Chemists Association, April 9, 2012).

"We have a human resource crunch, we are understaffed. We need 500 more drug inspectors" (Drug Regulatory Official, February 2, 2012).

Table 2. Number of Manufacturing Units, Sales Units, Inspections and the Actual and Required Numbers of Inspectors in India (2011-2012) and Three Study Districts (Dhule, Nagpur, and Sangli) 2009-2010

\begin{tabular}{|c|c|c|c|c|c|c|c|}
\hline & $\begin{array}{l}\text { No. of } \\
\text { Manufacturing } \\
\text { Units } \\
\text { (a) }\end{array}$ & $\begin{array}{l}\text { No. of Sales } \\
\text { Units }^{\mathrm{ab}} \\
\text { (b) }\end{array}$ & $\begin{array}{l}\text { Expected Inspections } \\
\text { Based on Drugs and } \\
\text { Cosmetics Act } \\
\text { (c) }=a+b\end{array}$ & $\begin{array}{l}\text { Actual Inspections } \\
\text { Conducted: Actual } \\
\text { (\% of expected) }\end{array}$ & $\begin{array}{l}\text { No. of Drug } \\
\text { Inspectors: } \\
\text { Appointed } \\
\text { (Sanctioned) }\end{array}$ & $\begin{array}{l}\text { Drug Inspectors Based } \\
\text { on Maharashtra } \\
\text { FDA Norm: Number } \\
\text { Required (Shortfall \%) } \\
\begin{array}{c}\text { (x) }=(a / 10 \times 12)+ \\
(b / 21 \times 12)\end{array}\end{array}$ & $\begin{array}{c}\text { Drug Inspectors Based } \\
\text { on Mashelkar Committee } \\
\text { Norm: Number Required } \\
\text { (Shortfall \%) } \\
\text { (y) }=(a / 50)+(b / 200)\end{array}$ \\
\hline $\begin{array}{l}\text { India (2011- } \\
2012)^{2}\end{array}$ & 10563 & $600000^{c}$ & 610563 & Data not available & 846 (1349) & 2469 (NA) & $3211(74)$ \\
\hline $\begin{array}{l}\text { Maharashtra } \\
(2009-2010)^{10}\end{array}$ & $1523^{a}$ & 80417 & 81940 & $19195(23)$ & $73(161)$ & $332(78)$ & $433(83)$ \\
\hline \multicolumn{8}{|c|}{ Study districts ${ }^{d}(2009-2010)^{10}$} \\
\hline Dhule & $10^{\mathrm{a}}$ & 2094 & 2104 & $238(11)$ & $0(N A)$ & $8(100)$ & $11(100)$ \\
\hline Nagpur & $95^{a}$ & 4039 & 4134 & $1010(24)$ & $4(6)$ & $17(76)$ & $22(82)$ \\
\hline Sangli & $32^{\mathrm{a}}$ & 2225 & 2257 & $246(11)$ & $1(4)$ & $9(89)$ & $12(92)$ \\
\hline
\end{tabular}

Abbreviations: FDA: Food and Drug Administration; NA, Information not available.

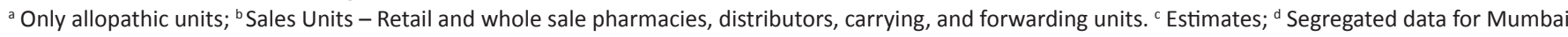
and Mumbai city district is not available. 
"In every district there are 3-4 posts for inspectors, but only one or two are actually filled" (Drug Inspector, January 17, 2012).

We asked key informants why sanctioned posts were not filled. Most of the regulatory officials were of the opinion that the availability of qualified and skilled human resources was not a barrier. On the contrary, they explained, there were ample training facilities for pharmaceutical education in Maharashtra:

"In Maharashtra good quality human resource is available. There are 407 institutes for pharmaceutical education and 29000 students are coming out every year from Maharashtra" (Drug Regulatory Official, February 2, 2012).

Respondents indicated concerns about the failure of those responsible for filling the posts to consider the relevant experience of those who better understood the needs. They told us that regulatory officials are not involved at any stage in the recruitment process conducted by the Maharashtra Public Service Commission ${ }^{19}:{ }^{[4]}$

"In Maharashtra 80 posts were vacant, and it took them 5 years to fill in those posts. So it is not that the government had not sanctioned the post. It is the way the public service commission operates; their selection was challenged, and finally the officers are appointed" (Retired Drug Regulatory Official, February 24, 2012).

Evidence from newspaper and Pharmabiz accounts indicates that there are a large number of applicants for positions of drug inspector. These sources also report that dissatisfied applicants often filed court cases when their applications were unsuccessful. These accounts show there was no shortage of applicants. Respondents explained that sanctioned posts remained unfilled because of a shortage of funds available to the state FDA, and a long and cumbersome recruitment process. Respondents at all levels were also of the opinion that there were no issues relating to retention of drug inspectors. Most thought that turnover rates were low (although they could not provide figures) and that staff were content with their compensation. Pay bands were adjusted every 5 years by the Pay Commission on the recommendation of the Central Pay Commission. Some key informants, however, suggested that lack of promotion was a problem. Most appointees who join as drug inspectors retire with the same designation or with only one grade of promotion over the course of their service.

Implications and Concerns About the Shortage of Drug Inspectors

One of the high-level regulatory officials as well as several district level officials admitted that they were non-compliant with the regulations, acknowledging that they could only complete $25 \%$ of the inspections of units required annually in Maharashtra:

"There are at least 75000 distribution and retail units and 1090 manufacturing units. Every unit must be inspected once in a year but it is not possible every time. Only about $25 \%$ of the distribution and retail units are inspected as frequently as 'once in a year"' (Drug Regulatory Official,

February 2, 2012).

To manage the workload, drug regulatory agencies at central and state levels implemented various strategies, such as special drives focusing on certain priorities. In such efforts to catch up, inspectors would not undertake a comprehensive inspection. They would focus instead on one or more selected issues, such as the availability of qualified pharmacists, the availability of specific medicines, storage conditions and stock management, so that they could cover more pharmacies.

Producers argued that Indian pharmaceutical companies would conform to self-regulation, because the confidence and faith of customers has substantial impact in a competitive market. Producers said that GMP certification based on the regularity of robust inspections is rigorous. They recognised the possibility that inspections might be unannounced:

"I want to make sure that drugs have adequate potency and efficacy when we manufacture and send them to the market. Because once you get a bad name, it is very difficult to get back the confidence of your customers. Now Indian companies are exporting to highly regulated markets. No manufacturer in his or her right mind really wants to be faulted in any way. Now many plants in India are approved by US FDA or EU's EMA. Now US FDA has an office in New Delhi. They can come and check within 24 hours. You can't afford to have deficiency in any way. You have to be compliant with all the procedures and processes and so on" (Pharmaceutical Producer, November 15, 2011).

Regulatory officials also reported that they focus more on those manufacturers who have a history of poor compliance: "Drug inspectors know which manufacturers have a good compliance record and those who are not having good compliance records. Those who are very good in selfregulation and very punctual and keen about compliance are not focused on by the Drug Inspectors" (Drug Regulatory Official, February 2, 2012).

The need for planning to cope with the proposed expansion of the capacity for testing samples in drug regulatory laboratories in Maharashtra was also recognized. Key regulatory officials reported that in Maharashtra, the two state-level laboratoriesone in Mumbai and the other in Aurangabad-had the capacity to test 8000 samples per year, which amounts to almost $20 \%$ of India's capacity. A senior official reported that Maharashtra had proposed scaling up its drug testing capacity tenfold, from 8000 to 80000 samples per year. This is almost double the country's current sample testing capacity. However, such aims to expand capacity for drug testing in new laboratories imply a complementary obligation to increase the number of drug inspectors. None of the respondents provided any indication of coordinated planning for that.

Members of the Druggists and Chemists Association in Maharashtra said that, despite issues related to a few stringent regulations, the association cooperates effectively with the state FDA to tackle issues related to substandard and spurious medicines, drug recalls and inspections:

"FDA does not trouble unnecessarily, but if the member is found non-compliant then FDA takes actions. The Association also does not support anyone who is doing wrong practices. We have a strong network of our members, which helps us in restricting entry of spurious drugs in our market and also during drug recalls" (Member of Druggists and Chemists Association, April 9, 2012).

Not surprisingly, in view of the accusations that have been leveled at Indian companies, producers reported that 
inspections were carried out with great efficiency:

"The GMP inspections are very rigorous. They check whether we are compliant with so many requirements; they really want a proof whether we have done it. If they are not satisfied, they do not give approval. The regular inspections are unannounced or surprise inspections" (Pharmaceutical Producer, November 15, 2011).

However, drug inspectors noted one barrier to effective inspections of distribution sites - the absence of a code of good distribution practices (GDP):

"Good distribution practices are not codified in India. You have licensing requirements wherein it would be specified as to how you deal with medicines, how you purchase, how you store, how you sell. That is a statutory requirement. But internationally, good storage practices and good distribution practices form part of either guidelines or the regulations. That is not the case under the drugs rules here" (Retired Drug Regulatory Official, February 24, 2012).

"There are two aspects, one is warehousing and the second one is transport. GDP is responsible for storage and not transportation. We call them wholesale licenses; whether he is a carrying and forwarding (C\&F) agent or a big distributor or a small distributor or a wholesaler, and once a year we do the inspection for most of them" (Drug inspector, January 17, 2012).

\section{Discussion}

This is the first study to identify the magnitude and examine the reasons for the shortfall of drug inspectors in the state of Maharashtra and in selected districts. Maharashtra has struggled to recruit the sanctioned 161 posts of drug inspectors. Though availability of skilled human resource was not perceived as a major problem in Maharashtra, delay in recruitment, court challenges, a slow recruitment process and lack of career opportunities were described as reasons for the continuing failure to reach the desired standards.

Despite the long list of job responsibilities of drug inspectors, ${ }^{13}$ both the State and Central governments are now expanding the role and increasing the workload of drug inspectors. For example, in addition to their current tasks, the CDSCO has proposed that drug inspectors will also inspect clinical trial sites once a year. ${ }^{20}$ Expanded capacity for lab testing will further add to drug inspectors' workloads. They will receive reports more quickly, and they will be expected to follow up on more samples collected during inspections.

The Mashelkar Committee noted that India has well-drafted legislation, which is in line with recommendations of the WHO 2002 multi-country study for effective regulations, but that its enforcement at several levels has been inconsistent because of the multiplicity and the variable quality of the enforcement authorities. ${ }^{15}$ The WHO study recommended a single countrywide agency to prevent fragmentation and uncoordinated delegation of powers that impede regulatory effectiveness. ${ }^{15,18}$

Since 1975 several committees and reports have recommended establishing a National Drug Authority (NDA). ${ }^{14,15}$ The Pharmaceutical Research and Development Committee (1999) and Drug Policy (2002), as well as the Mashelkar Committee, all recommended the comprehensive strengthening of the CDSCO as an alternative to a new NDA. ${ }^{15}$
This recommendation has still not been implemented, ${ }^{2,17}$ however, nor has an NDA been established.

The gap remains between national statutory provisions for inspection and workforce planning norms. One solution is to put in place primary legislation, the Act, to provide that both Central and State authorities shall have the 'duty' to appoint a sufficient number of qualified inspectors who shall be given such powers and duties as are necessary for ensuring that the Central and State authorities are able to perform their respective functions effectively under the Act.

The Government of India, in its secondary legislation, the Rules, should then prescribe norms for calculating the number of such inspectors at the level necessary for ensuring effective performance. Inspection norms need to be separately provided under a new Rule. ${ }^{13}$ These Rules should also include provisions for reassessing inspection norms to account for growth and increasing complexity of the pharmaceutical industry and for future expansion of role of drug inspectors (eg, inspection of clinical trial sites).

Greater transparency in the functioning of the drug regulatory authorities is essential. The support of WHO and international agencies in strengthening the public regulation system and in the inspection of the indigenous pharmaceutical industry is crucial for the interests of safer and efficacious medicines for India and for its prospects in international trade. Failure to achieve a better regulatory capacity on a country-wide basis is likely to jeopardize the health of Indian citizens and could also trigger an international ban on medicines manufactured in India under the public health protection sections of the General Agreement on Tariffs and Trade (GATT) or technical barriers to trade (TBT) agreements. Consequently, a central database needs to be created and made available in the public domain in order to enable public scrutiny of the work of the regulatory agencies.

\section{Recommendations}

- The Government of India should constitute a committee, with a clear process and timeline, to develop 'workforce planning norms' based on the recommendations of the Mashelkar Committee and global standards, and to consider whether primary legislation and Rule changes are required.

- This committee should assess the implementation status of recommendations by these various previous committees.

- This committee should promote, support and assess initiatives to create a central as well as state-level databases, and work to make them available in the public domain.

\section{Conclusion}

Astronginspectorateisacrucialpartofanoveralldrugregulatory system. It is an indicator of the rigour and competence of the regulatory body in fulfilling its responsibilities for oversight of the manufacturing and marketing of pharmaceuticals. To achieve this goal, the Government of India needs to assess urgently the implementation status of recommendations of the various committees that have reported on this topic in the past 15 years. It needs to ensure that global standards are in place and to make reliable information available in the public 
domain.

\section{Acknowledgements}

This paper results from research funded by the European Union Seventh Framework Programme Theme: Health-2009-4.3.2-2 (Grant no. 242262) under the title 'Access to Medicines in Africa and South Asia (AMASA).' The project team includes partners at the Swiss Tropical and Public Health Institute, an associated institute of the University of Basel (Basel, Switzerland), University of Edinburgh (Edinburgh, UK), The Queen Mary University (London, UK), University of Ghent (Ghent, Belgium), Makerere University (Kampala, Uganda) Mbarara University of Science and Technology (Mbarara, Uganda), University of the Western Cape (Cape Town, South Africa), and the Foundation for Research in Community Health (Pune, India). Neither the European Union (EU) nor any of the partner institutions is responsible for views advanced here. We also like to acknowledge the Tata Steel for financially supporting the author during writing stage. The authors are also grateful to the FRCH AMASA research team for contributing in data processing including translation and transcriptions of qualitative interviews and managing field level logistics.

\section{Ethical issues}

The research proposal was cleared (IEC/2011/01/1.1) by the Institutional Research Ethics Committee of the Foundation for Research in Community Health and by the ethical review procedures of the School of Social and Political Science, University of Edinburgh, Edinburgh, UK.

\section{Competing interests}

Authors declare that they have no competing interests.

\section{Authors' contributions}

Concepts, Design, manuscript preparation, manuscript editing, and manuscript review: $A B K, K M, R J, N F M, M G W$, and AMP; Literature search: ABK; Data acquisition and data analysis: $A B K, K M$, and AMP; Guarantor: ABK. All of the authors played an important role in the acquisition, analysis and interpretation of the data; made substantial suggestions for the revisions of the manuscript; and approved the final submitted version of the paper.

\section{Endnotes}

[1] Category 1 states include Maharashtra, Gujarat, Tamil Nadu, Andhra Pradesh, Karnataka, West Bengal, and Goa (Mashelkar Committee report, 2003).

[2] Subs. by G.S.R 601 (E), dt. 24-8-2001.

[3] Subs. by G.S.R. 700 (E), dt. 28-9-2001.

[4] Such court challenges not only delay the appointment of drug inspectors but also higher level officials in India. The appointment of the Drugs Controller General India was also delayed in this way (see reference 19).

\section{Authors' affiliations}

${ }^{1}$ The Foundation for Research in Community Health (FRCH), Pune, India. ${ }^{2}$ Department of Epidemiology and Public Health, Swiss Tropical and Public Health Institute (Swiss TPH), Basel, Switzerland. ' $U$ niversity of Basel, Basel, Switzerland. ${ }^{4}$ Centre for South Asian Studies, School of Social and Political Science, University of Edinburgh, Edinburgh, UK. ${ }^{5}$ Global Public Health Unit, Queen Mary University of London, London, UK.

\section{References}

1. Greene W. The Emergence of India's Pharmaceutical Industry and Implications for the US Generic Drug Market; 2007.

2. Parliamentary Standing C. 59th report on the functioning of the Central Drugs Standard Control Organisation (CDSCO):
Department Related Parliamentary Standing Committee on Health and Family Welfare (2011-2012). New Delhi, Rajya Sabha; 2012.

3. Bate R. Cheap Indian generic drugs: Not such good value after all? American Enterprise Institute. Published February 2013.

4. Bate R, Tren R, Mooney L, et al. Pilot study of essential drug quality in two major cities in India. PLoS One. 2009;4(6):e6003. doi:10.1371/journal.pone.0006003

5. Brhlikova P, Harper I, Jeffery R, Rawal N, Subedi M, Santhosh M. Trust and the regulation of pharmaceuticals: South Asia in a globalised world. Global Health. 2011;7:10. doi:10.1186/17448603-7-10

6. Caudron JM. Substandard medicines in resource-poor settings: a problem that can no longer be ignored. Tropical Medicine \& International Health. 2008;13(8):1062-1072. doi:10.1111/j.13653156.2008.02106.x

7. Nelson D. Britain ignored warnings of Indian whistleblower at heart of drugs scandal. The Telegraph. June 13, 2013. http:// www.telegraph.co.uk/news/worldnews/asia/india/10119371/ Britain-ignored-warnings-of-Indian-whistleblower-at-heart-ofdrugs-scandal.html

8. Vidya K, Unnikrishnan $\mathrm{CH}$. Ranbaxy fallout: Indian pharma under the microscope. Live mint website. http://www.livemint. com/Industry/nTIfqyG87wxdlz8txCa6HL/Indian-pharma-underthe-microscope.html. Published May 23, 2013.

9. Department of Pharmaceuticals. Annual report 2011-2012. http:// pharmaceuticals.gov.in/AnnualReportEnglish.pdf. Published on 2012.

10. Government of Maharashtra. Medical Education and Drugs Department, Annual Plan 2011-2012. Mumbai; 2011.

11. FDA prohibits Ranbaxy's Toansa, India facility from producing and distributing drugs for the U.S. market. http://www.fda.gov/ NewsEvents/Newsroom/PressAnnouncements/ucm382736. htm. Published 2014.

12. DCGI asked to check quality of drugs sold by Ranbaxy. The Hindu, Business Line website. http://www.thehindubusinessline. com/economy/dcgi-asked-to-check-quality-of-drugs-sold-byranbaxy-govt/article5051958.ece. Published August 23, 2013

13. Drugs and Cosmetics Act 1940 and Drugs and Cosmetics Rules 1945. 2013.

14. Hathi C. Hathi Committee Report. Government of India; 1975.

15. Mashelkar C. Mashelkar Committee Report, Report of the Expert Committee on a Comprehensive Examination of Drug Regulatory Issues, Including the Problem of Spurious Drugs. New Delhi: Government of India; 2003.

16. Lentin C. Lentin Commission Report, Report of the Commission of Inquiry (Re Deaths of Patients in $\mathrm{J} \mathrm{J}$ Hospital at Bombay in January- February 1986 due to alleged reaction of drugs); 1988.

17. Planning Commission. The report of the working group on Drugs and Pharmaceuticals for the formulation of the Twelfth Five Year Plan (2012-2017). http://planningcommission.gov.in/aboutus/ committee/wrkgrp12/health/WG_4drugs.pdf. Published 2012.

18. World Health Organization (WHO). Multicountry Study on Effective Drug Regulation. Geneva: WHO; 2002.

19. Ramesh S. Even after one year of SC directive, Madras $\mathrm{HC}$ yet to hold final hearing in controversial DCGI case. Pharmabiz website. http://www.pharmabiz.com/NewsDetails. aspx?aid=77035\&sid=1. Published August 08, 2013.

20. Dey S. Drug regulator to periodically inspect all clinical trial sites. Business Standard website. http://www.business-standard. com/article/companies/drug-regulator-to-periodically-inspectall-clinical-trial-sites-113050600006_1.html. Published May 6, 2013. 